\title{
DYNAMICS OF HIGHLY ENERGETIC ELECTRONS IN NOVEL ACCELERATING DIODES*
}

\author{
Ben Crampsey, Philip MacInnes, Kevin Ronald, \\ and Alan D. R. Phelps, \\ SUPA, Physics Department, University of Strathclyde, \\ Glasgow G4 ONG, UK
}

We present initial predictions from the investigation of a novel, short-pulse ( $200 \mathrm{~ns})$, space-charge-limited-emission electron accelerating diode, or electron-gun, that operates purely under the influence of its own self-fields - i.e. without the requirement for externally applied magnetic insulation of the propagating electron beam. The optimised model, developed using CST Studio Suite, predicted a $\sim 500 \mathrm{keV}, \sim 1.86 \mathrm{kA}$ electron beam, with a mean envelope-radius of $16.8 \mathrm{~mm}$ propagating into a $18 \mathrm{~mm}$ radius drift-tube. The beam was very slightly convergent at the entry to the drift-region with a convergence angle of $1.5^{\circ}(0.026 \mathrm{rad})$.

A key consideration, in developing the electron gun, was the potential for vacuum-arcing, due to excessive electric field stresses. The pulsed nature of the gun aids in mitigating some of that risk, however to reduce it further, the maximum fieldstress considered "safe" was taken to be $\sim 40 \mathrm{MV} / \mathrm{m}$ (double the typical Kilpatrick DC limit of $20 \mathrm{MV} / \mathrm{m}$ ). In the optimized model the peak stress was $\sim 35 \mathrm{MV} / \mathrm{m}$, falling acceptably within the bounds set.

The electron gun is currently being manufactured for experimental testing, where it will then be used as the particle accelerator driving a novel, self-insulating, high-power microwave source.

\footnotetext{
*Work supported by the Office of Naval Research, Grant No. N62909-18-1-2122- GRANT12538355, N00014-18-S-B001

Ben Crampsey supported by the EPSRC Summer Internship Scheme for undergraduate students.
}

Crampsey, B., MacInnes, P., Ronald, K., \& Phelps, A. D. R. (2020). Dynamics of highly energetic electrons in novel accelerating diodes. Abstract from 47th IEEE International Conference on Plasma Science. 